\title{
A Note to Introduce Steve Lambert's Art and Fear of Propaganda
}

\section{SARAH COOK}

Professor, University of Glasgow

I will not make any more boring art. I will not make any more boring art. I will not make any more boring art. These lines, written at the instruction of artist John Baldessari in 1971, are now a well-known work of conceptual art. The work was an instruction to students at the Nova Scotia College of Art and Design, and in sharing the work with us in the form of a lithograph, the students turned the work into a manifesto. The key thing about manifestos is that they are public. They suggest an intended course of action, asking us to act in accordance with rules that the writer of the manifesto feels should be shared. For example, point 2 of The Law of Sculptors (1969) written by artists Gilbert and George says, "Make the world believe in you and to pay heavily for this privilege." Not all artists might agree to follow a manifesto written by another artist, though Baldessari's is a good one to start with.

Manifestos written by artists proclaim ways to live life and how to make life into art and vice versa. The Futurists, for example, released rules for hosting challenging dinner parties, and their entire manifesto was about radical revolution: "The poet will have to do all in his power, passionately, flamboyantly, and with generosity of spirit, to increase the delirious fervour of the primordial elements." Recipes are created from rules. Conflict between ingredients creates interesting dishes. The oven is a tool that has to be manipulated with care to result in a palatable experience. This analogy of meal-making is fitting because it is both a shared experience and is also akin to art-making and the experience of encountering art (I like it! I don't like it!). As a cook uses an oven, so do artists use tools, and the use of those tools is governed by practice but also limited by engineering and design. Many manifestos written by artists reflect on the tools of art-making and suggest ways to use them to change the world; for example, the Futurist $L A$ RADIA Manifesto explored the use of radio and eventually TV, and VALIE EXPORT's Women's Art Manifesto from 1972 read, "We women must participate in the construction of reality via the building stones of media-communication."

With conceptual art there is no tool other than the mind, and the language and words which communicate the idea from the mind of the artist. Therefore much rule-based work of the 1960s and 1970s is manifesto-like. The history of rule-based conceptual art is closely tied to the history of performance art. Yoko Ono's work is rife with instructions, like recipes for things to do, such as to pick up a pair of scissors and cut her clothes, in Cut Piece (1964). The more radical rulebased performances were often by women who put forward their bodies as one of the tools to activate. Marina Abramović invited audiences to use any number of objects on a table next to her, including weapons, in Rhythm 0 (1974). 
Whether or not it is a precondition for being an artist that you write a manifesto or even share your own personal rules for art-making, it seems that with the advent of technology a number of artists have moved to creating work that asks us as viewers and participants to engage in a system of their creation or to use tools to change the system. Gustav Metzger's Manifesto For AutoDestructive Art was very clear on this, mentioning the possibility of collaboration with engineers in reshaping technological society.

Steve Lambert's "Art and Fear of Propaganda" is not quite a manifesto and not quite a set of rules but something in between. In fact a number of Steve's works do have rules, mostly rules of engagement. The Anti-Advertising Agency asked advertisers to quit their jobs and rewarded them if they did. Lambert's work Capitalism Works for Me is a voting machine with a binary choice yes or no. To participate you have to cast your vote and talk with the attendant about your choice. While this seems to turn the viewer into the performer, it is still primarily a mental exercise. Voting is not a performance - it has real consequences. Voting is not something you usually do publicly and you do not necessarily share your choice with others. Voting sits within a system of news and information that shares the collective results. The information you have determines your choice of answer to a given question. The artist Hans Haacke has exploited this method in using audiences as the subject and object of his work such as MoMA Poll (1970), inviting them to fill in surveys or answer questions yes or no and reveal their answers for others to see. Lambert is no doubt aware of these notable precedents in the history of art and of the moment in the 1960s when art and life were blurred through performative gestures acted out in public spaces such as exhibitions, museums, and of course on the street.

In Art and Fear of Propaganda Lambert makes a link between available information and propaganda. He sets out a series of concerns, almost like rules for how to engage in systems that seek to influence behavior and thought. The next step in this evolution is of course the artist working with the machine (whether a specific tool or an emerging technology, like social media and their algorithmic biases), programming it with specific rules for specific outcomes. 